\title{
An Overview of the Clinical Use of Antimuscarinics in the Treatment of Overactive Bladder
}

\author{
Anastasios Athanasopoulos and Konstantinos Giannitsas \\ Urodynamic Urology Unit, Department of Urology, Medical School, University of Patras, 26500 Patra, Greece \\ Correspondence should be addressed to Anastasios Athanasopoulos, tassos_athan@hotmail.com
}

Received 26 February 2011; Accepted 13 April 2011

Academic Editor: Yasuhiko Igawa

Copyright ( $) 2011$ A. Athanasopoulos and K. Giannitsas. This is an open access article distributed under the Creative Commons Attribution License, which permits unrestricted use, distribution, and reproduction in any medium, provided the original work is properly cited.

\begin{abstract}
Overactive bladder is a common and bothersome condition. Antimuscarinic agents, as a class, are the cornerstone of medical treatment of overactive bladder. They offer significant improvements in symptoms and patients' quality of life. Antimuscarinics are generally well tolerated with mild and predictable side effects. Available antimuscarinics have small, yet statistically significant, differences in their efficacy and tolerability profiles. In clinical practice, finding the agent that offers the optimum balance of efficacy and side effects for an individual patient remains the major challenge.
\end{abstract}

\section{Introduction}

Overactive bladder $(\mathrm{OAB})$ is a lower urinary tract condition, characterized by symptoms of urgency, with or without urge incontinence, usually with frequency and nocturia. This symptom complex significantly affects patient's quality of life. In most cases, the underlying pathophysiology is an involuntary detrusor contraction during the storage phase of the voiding cycle [1].

Normal bladder contraction during voiding involves stimulation of the muscarinic receptors on the detrusor muscle by acetylcholine (Ach). The role of Ach in the pathogenesis of involuntary contractions during the storage phase is elusive. Despite the fact that detrusor may contract spontaneously, as a result of the intrinsic activity of the myocyte or of small units of smooth muscle cells [2], Ach is still released from the nerves or from nonneurogenic sources, like the urothelium. A direct or indirect effect of Ach should be considered [2]. Muscarinic receptors are also found on the presynaptic nerve terminals to the bladder participating in the regulation of transmitter release. Currently, there is increasing evidence for an important role of afferent pathways in the pathophysiology of involuntary detrusor contractions [2,3]. Antimuscarinics, which block muscarinic receptors, have been the treatment of choice for overactive bladder for decades. They affect the efferent control on detrusor contraction, but increasing evidence also suggests a role in afferent pathways' regulation.

There are several subtypes of muscarinic receptors. The human detrusor contains mainly the $\mathrm{M}_{2}$ and $\mathrm{M}_{3}$ subtypes [4]. Available antimuscarinics vary in their selectivity for muscarinic receptors.

Oxybutynin [5-8], Tolterodine [9], propiverine [10], solifenacin $[11,12]$, darifenacin $[13,14]$, trospium $[15,16]$, and fesoterodine [17] are antimuscarinic agents approved for use in $\mathrm{OAB}$ treatment. Evidence on the efficacy and safety of these agents as a class is reviewed here, and issues concerning their clinical application are discussed.

\section{Materials and Methods}

The current literature on the efficacy and safety of antimuscarinics was reviewed by searching Medline/PubMed for relevant articles, published in English between 1980 and 2010.

\section{Results and Discussion}

\subsection{Antimuscarinics}

3.1.1. Oxybutynin. Oxybutynin is the first antimuscarinic used for the treatment of OAB. In addition to its 
antimuscarinic action, oxybutynin in high doses exerts muscle-relaxant and local anaesthetic effects [5-8].

Oxybutynin is now available in oral, immediate (IR) and extended release (ER), as well as two transdermal formulations, a patch and a gel. An intravesical formulation of oxybutynin has also been studied [18].

Oxybutynin IR formulation was the fist that entered clinical practice. Despite its satisfactory efficacy, the substantial incidence of dry mouth, immediate release oxybutynin's most common and bothersome side-effect, limited its tolerability. Newer formulations aimed at eliminating peaks in concentration of oxybutynin and its metabolites in order to reduce related side effects.

The ER formulation of oxybutynin provides a smooth plasma concentration profile over the 24-hour dosage interval, facilitating once-daily administration. Hence, given its overall efficacy/tolerability and dose flexibility, oxybutynin ER provides an alternative in the first line of pharmacotherapy for OAB [8]. Overall, as shown in the OPERA study [19], oxybutynin ER has modestly greater efficacy than tolterodine ER at its most commonly prescribed dose. In the OBJECT study, oxybutynin ER was more effective than tolterodine IR at the endpoints of urge incontinence, total incontinence, and micturition frequency episodes [20].

The transdermal oxybutynin (OXY-TDS) formulation offers patients with urinary incontinence an effective, safe and well-tolerated option for managing the symptoms of overactive bladder $[7,21]$. As OAB contributes to decreased work productivity due to job interruptions as well as fatigue, the use of OXY-TDS may result in productivity improvement when patients receive $3.9 \mathrm{mg} /$ day via twice weekly patch application for up to 6 months [22].

Oxybutynin chloride topical gel (OTG) was approved in January 2009 by the US FDA. OTG was designed to provide steady plasma oxybutynin levels with daily application, favorably altering the circulating $\mathrm{N}$-desethyloxybutynin metabolite to oxybutynin ratio, thus minimizing the antimuscarinic adverse effects of oral formulations. The use of a biocompatible delivery system also reduced the application-site skin reactions associated with other available forms of transdermal delivery. OTG represents an efficacious, safe, and convenient alternative to other oxybutynin formulations and oral antimuscarinics for the treatment of $\mathrm{OAB}$ [23].

Interestingly, all the above-mentioned oxybutynin formulations have been shown to be more efficacious than the IR oxybutynin $[24,25]$ in respective trials.

3.1.2. Tolterodine. Tolderodine is a widely prescribed antimuscarinic and, it was the first specifically developed to treat $\mathrm{OAB}$. Tolterodine is not selective for any muscarinic receptor subtype, but it exhibits selectivity for the urinary bladder over salivary glands in vivo [26].

An IR formulation was available first, but an ER, administered once daily, formulation was later designed. Its efficacy and tolerability have been proved in a large number of trials [27]. Tolterodine offers significant improvement in overactive bladder symptoms and quality of life while having a favorable safety profile. It soon became the gold standard in the class, a drug that all others are compared to, during their clinical development.

Oxybutynin and tolterodine, the until relatively recent years most commonly prescribed antimuscarinics, have been shown to have similar efficacies in general OAB populations [28], as well as in specific subpopulations defined by severity of urodynamic findings [29].

3.1.3. Propiverine. Propiverine, another muscarinic receptor antagonist, has also been demonstrated to inhibit L-type $\mathrm{Ca}^{++}$channels in high concentrations [30].

Propiverine has similar efficacy to oxybutynin and tolterodine, similar tolerability and impact on quality of life to tolterodine, but a better tolerability profile than oxybutynin $[31,32]$. This drug is well tolerated [33].

Propiverine and oxybutynin are efficacious in children with incontinence due to overactive bladder and propiverine is officially approved in certain countries for pediatric use. Alloussi et al. [34] evaluated existing evidence for the use of antimuscarinics in children. They concluded that highquality studies are still limited and results vary widely across antimuscarinics. This fact is associated with different levels of evidence and grades of recommendation for children for oxybutynin $(3 \mathrm{C})$, propiverine $(1 \mathrm{~B} / \mathrm{C})$, tolterodine $(3 \mathrm{C})$, and trospium chloride $(3 \mathrm{C})$, awarded by the International Consultation on Incontinence. The daily urgency episodes were significantly reduced from baseline to 12 weeks on propiverine treatment, compared with placebo. Secondary endpoints, including sum of urgency severity per $24 \mathrm{~h}$, urgency severity per void, and daytime voiding frequency, were also improved significantly in the propiverine group [35].

3.1.4. Darifenacin. Darifenacin is the antimuscarinic with the highest M-3 receptor subtype selectivity. Long-term darifenacin treatment was associated with significant and clinically meaningful improvements in quality of life of patients with urge incontinence ("wet" OAB) over 2 years [36]. In a study of patients who were dissatisfied with their previous treatment with oxybutynin ER or tolderodine ER, patients perception of bladder condition (PPBC) score and OAB symptoms were significantly improved, and satisfaction was high during treatment with darifenacin 7.5 or $15 \mathrm{mg}$ [37]. Haab [14] in a comprehensive review described the good clinical efficacy and safety profile of this agent.

3.1.5. Solifenacin. A pooled analysis of four randomized, placebo-controlled, phase III studies of solifenacin in $\mathrm{OAB}$ patients without incontinence, showed a significant improvement of symptoms and voided volume after 12 weeks of treatment [38].

How does solifenacin compare to longer established antimuscarinics? One comparison of the "new" (solifenacin and darifenacin) and "old" antimuscarinic agents showed the two generations of treatment had similar efficacy $[35,39]$. A randomized, double-blind study found that solifenacin is superior to an encapsulated formulation of tolterodine ER in most of the efficacy outcomes [40]. The majority of side effects were mild to moderate in nature, yet significantly 
more for solifenacin, and discontinuations were comparable and low in both groups. This study investigated both approved doses of solifenacin, $5 \mathrm{mg}$ and $10 \mathrm{mg}$, and was, therefore, criticized for using doses not directly comparable to tolterodine $4 \mathrm{mg}$. A subanalysis of this study [30] subsequent compared solifenacin $5 \mathrm{mg}$ and tolderodine $4 \mathrm{mg}$ and better reflected treatment outcomes with the doses most commonly used in clinical practice, at least during treatment initiation. It concluded that after a 4-weeks treatment period, solifenacin $5 \mathrm{mg}$ significantly improved incontinence symptoms and reduced the use of incontinent pads, compared to tolterodine. In another, randomized, placebo-controlled study, Cardozo et al. [41] found that solifenacin significantly reduced the number of urgency episodes and urgency bother and was well tolerated. Treatment was effective as early as day 3.

Solifenacin is the first antimuscarinic to demonstrate significant warning-time improvement in a large $O A B$ clinical trial conducted to evaluate warning time and diary variables in the same study population [42].

A relatively recent comprehensive review for solifenacin concluded that this agent was effective in the treatment of $\mathrm{OAB}$ with urge incontinence [12].

3.1.6. Trospium. Trospium chloride is a quaternary ammonium compound. It does not cross the blood-brain barrier; therefore, no central nervous system adverse events are anticipated [16]. This drug significantly reduces UUI and frequency compared with placebo [43]. Compared to tolderodine, trospium reduced the frequency of micturition and incontinence episodes. Extended-release trospium chloride $60 \mathrm{mg}$, a novel modified-release form of this compound allows once-daily administration, potentially enhancing compliance to treatment and improving its clinical efficacy/tolerability profile, compared with immediaterelease form [44]. Cardozo et al. [44] in a recent publication underlined that the extent of metabolism of this drug is low and independent of the liver cytochrome P450 isoenzyme system. This pharmacodynamic profile further simplifies decision making in polypharmacy situations, such as multimorbid and elderly patients. Furthermore, subject to predominantly renal elimination as the unchanged form, trospium chloride retains its pharmacological activity within the urinary bladder, and local action on urothelium muscarinic receptors is supposed to contribute to its early onset and sustained efficacy in controlling urgency.

3.1.7. Fesoterodine. Fesoterodine is the newest antimuscarinic for the treatment of OAB. Fesoterodine is a prodrug. It is rapidly and extensively hydrolyzed by nonspecific esterases, thus bypassing the CYP system, to 5hydroxymethyl tolderodine (5-HMT), which is also the active metabolite of tolderodine. Interestingly, as 5-HMT formation from fesoterodine occurs via ubiquitous nonspecific esterases, the rate of fesoterodine hydrolyzation maybe more uniform and complete.

Initial data from phase 2 trials showed that fesoterodine was an effective and well-tolerated therapy for OAB [45]. In subsequent clinical studies, fesoterodine doses of 4 and
$8 \mathrm{mg} /$ day were consistently superior to placebo in improving overactive bladder symptoms, with $8 \mathrm{mg} /$ day having significantly greater effects than $4 \mathrm{mg} /$ day [17]. Both doses were safe and well tolerated, with a low overall incidence of adverse events. Tolerability is comparable to that of tolderodine (ER) [46].

In a posthoc analysis of pooled data from two clinical trials including 1,548 women with overactive bladder, fesoterodine $4 \mathrm{mg}$ and $8 \mathrm{mg}$ and tolderodine showed significant improvements in all bladder diary variables assessed and greater response rates versus placebo. Fesoterodine $8 \mathrm{mg}$ was significantly more efficacious than fesoterodine $4 \mathrm{mg}$ and tolderodine ER in improving UUI episodes and continence days per week [47]. Recently, the FACT study, a head to head placebo controlled trial, compared the efficacy and tolerability of fesoterodine $8 \mathrm{mg}$ with tolderodine ER $4 \mathrm{mg}$. This study was designed to asses the superiority of fesoterodine over tolderodine ER for the treatment of $\mathrm{OAB}$ symptoms, and 1697 patients were included. This trial concluded that in patients with $\mathrm{OAB}$, fesoterodine $8 \mathrm{mg}$ showed superior efficacy over tolderodine ER $4 \mathrm{mg}$ and placebo in reducing UUI episodes and in improving most patient-reported outcome measures. Both active treatments were well tolerated [48]. In another recent study, the flexible dose of fesoterodine was evaluated. Among 516 subjects treated, approximately $50 \%$ opted for dose escalation to $8 \mathrm{mg}$ at week 4 . The study concluded that flexible dose fesoterodine significantly improved $\mathrm{OAB}$ symptoms health related quality of life (HRQOL) and rates of treatment satisfaction and was well tolerated in patients with $\mathrm{OAB}$ who were dissatisfied with prior tolderodine therapy [49].

3.2. Efficacy and Safety. Currently available antimuscarinics have all demonstrated their efficacy and safety in welldesigned, controlled studies conducted during their clinical development. The significant placebo effect observed in $\mathrm{OAB}$ trials and the frequent treatment discontinuations in real-life practice have often raised doubts regarding the true efficacy and/or safety of this drug class. Systematic reviews and metaanalyses of existing data have tried to clarify uncertainties.

In 2003, Herbison et al. [39] have published a systematic review of randomized controlled trials comparing antimuscarinic agents to placebo in the treatment of OAB. The authors concluded that antimuscarinic drug therapy provided significant improvement in $\mathrm{OAB}$ symptoms, such as urge incontinence episodes and micturition frequency over placebo. Significant improvements, compared to placebo have also been demonstrated for urodynamic parameters. However, the magnitude of treatment effect was smaller than the anticipated based on clinical experience with antimuscarinics. A possible explanation for this is the common combination of medical treatment and bladder training in clinical practice. In the majority of clinical trials, formal bladder training is not included.

A 2005 systematic review of 52 randomized, controlled trials by Chapple et al. [50], which was latter updated with more studies in 2008 [51], showed that antimuscarinics, as a class, significantly reduce urge incontinence episodes, making many patients continent, and provide significant 
improvements in quality of life. They also reduce the severity of urgency and decrease micturition frequency. Individual antimuscarinics were effective in at least one of the outcome measures included in the reviews. Profiles of each drug and dosage differ and should be considered in making treatment choices. Despite abundance of evidence on the short-term efficacy of antimuscarinics, Chapple et al. noted a lack of knowledge regarding issues of chronic treatment, given that followup in most trials is short.

Differences in efficacy of antimuscarinics have often reached statistical significance in clinical trials. Nevertheless, the magnitude of these differences is not readily appreciated in everyday clinical practice and many clinicians consider drugs in this class as "comparable" in terms of efficacy. According to a meta-analysis by Novara et al. [24], efficacies of available antimuscarinics are comparable. Nevertheless, if factors such as safety, tolerability, and cost are to be taken into account, Oxybutynin ER, tolterodine ER $4 \mathrm{mg}$, solifenacin $5 \mathrm{mg}$, or solifenacin $10 \mathrm{mg}$ can be considered the first-line treatment choice. Darifenacin $15 \mathrm{mg}$ and fesoterodine $4 \mathrm{mg}$ are alternatives although more data are needed. In cases of lack of efficacy of first-line ER drug, fesoterodine $8 \mathrm{mg}$ and solifenacin $10 \mathrm{mg}$ might be secondline treatment, given that their efficacy is superior with only a small compromise in tolerability.

As far as safety is concerned, antimuscarinics, in general, are safe $[24,52,53]$. The "older" drugs oxybutynin and tolterodine have been more thoroughly studied $[54,55]$. Side effects are due to muscarinic receptor binding in organs other than the bladder. The effects of antimuscarinics on salivary glands are responsible for the most common and bothersome side effect, dry mouth. Other unwanted effects include constipation, blurred vision, somnolence, dizziness and cognitive impairment. Untreated, close-angle glaucoma is a contraindication for antimuscarinics.

Slight differences in the safety profiles of existing antimuscarinic agents depend on their selectivity for specific muscarinic receptor subtypes, selectivity for the bladder compared to salivary glands, their lipophilicity and ability to cross the blood-brain barrier, as well as their pharmacokinetic properties.

Evidence from controlled trials [50] suggests that antimuscarinics are well tolerated compared with placebo, with the exception of immediate-release (IR) oxybutynin. Extended-release (ER) tolterodine is the only formulation with fewer total treatment discontinuations compared with placebo, a finding that just reached statistical significance.

In general, the extended release formulations are better tolerated than the immediate release ones. In cases that dry mouth is intolerable with the oral formulations, transdermal oxybutynin might bean alternative, but, unfortunately, application site reactions are common with the oxybutynin patch [21]. Solifenacin and darifenacin are believed to be associated with higher rates of constipation [24] compared to other antimuscarinics. Nevertheless, a recent meta-analysis of randomized, placebo-controlled trials has shown high odds ratios for constipation, compared with placebo, for other drugs as well [56].
Central nervous system side effects are a concern when prescribing antimuscarinics for the treatment of $\mathrm{OAB}$, particularly in vulnerable populations such as the elderly and CNS-compromised, neurogenic bladder patients. The evidence for cognitive impairment with oxybutynin is compelling [57]. Darifenacin with low CNS penetration and selectivity for the M3 over the M1 muscarinic receptor subtype is expected to cause less cognitive impairment. Indeed, in a short term study, darifenacin did not have any effect on the cognitive function [58]. Moreover, a review of available literature [59] concluded that darifenacin did not cause an impairment of memory among other cognitive functions. Trospium chloride is another drug that does not cross the blood-brain barrier and in a recent study it was undetectable in the older human central nervous system [60]. Fesoterodine is considerably less lipophilic than tolderodine [61] which has minimal or no cognitive effects.

The binding of muscarinic receptors in the heart may lead to cardiovascular adverse events and QT interval prolongation has been a concern with antimuscarinics. In a randomized, double-blind, placebo-controlled, crossover trial [62], tolterodine significantly increased heart rate versus placebo and darifenacin did not affect heart rate compared to placebo. Darifenacin does not prolong QT/QTc interval [63]. An older study showed that Oxybutynin is not associated with a corrected QT interval prolongation and is unlikely to induce ventricular arrhythmias [64]. It seems that tolterodine does not have a clinically significant effect on QT interval [65]. Propiverine provoked a statistically significant increase in the mean QTc interval but without clinical arrhythmic events [66]. The newest antimuscarinic drug fesoterodine is not associated with QTc prolongation or other ECG abnormalities at either therapeutic or supratherapeutic doses [67]. In a study with real-life conditions, that is, with inclusion of large numbers of patients with cardiovascular comorbidities and taking several other medications, therapeutically effective doses of solifenacin did not increase heart rate or blood pressure [68].

\subsection{Special Treatment Issues}

3.3.1. Treatment Compliance. Despite acceptable rates of treatment discontinuation in clinical trials, real-life compliance, especially to long-term treatment, is low. For example, in a pharmacy dispensing records review for antimuscarinic agents from January 2003 to December 2006 conducted for the United States Military Health System National Capital Region, 35\% of OAB patients did not refill a fully reimbursed prescription for antimuscarinics [69]. In another study, $44.5 \%$ of patients did not renew their first prescription of antimuscarinics [70]. In observational trials, under reallife conditions, discontinuation rates for tolterodine, for example, have been reported to be as high as $49 \%$ at 6 months followup [71]. Overall, adherence is significantly better for extended release than immediate release agents.

Low compliance to treatment can be due to inadequate drug efficacy, intolerable side effects, poor patient education and follow up, and cost issues. Among these reasons dry mouth is the most common [51, 72]. In every-day 
clinical practice, unmet expectations may represent another important reason for treatment discontinuation [73, 74]. Selecting the appropriate drug for each patient, the one that offers the best balance between efficacy and adverse events would be a very important step in improving adherence to treatment. Patient education on $\mathrm{OAB}$ and its treatments and patient reassurance when side effects occur represent other important strategies in improving compliance. Realistic patient expectations from treatment are a prerequisite for treatment success.

3.3.2. Dose Flexibility. Dose flexibility offers the advantage of an individually tailored treatment to achieve the optimum balance between efficacy and adverse events. A strategy based on patient-requested dose increases has been found to consistently improve overactive bladder symptoms. The impact of dose flexibility on clinical management of OAB has been examined in studies with solifenacin, darifenacin, and oxybutynin ER [75]. Patients requesting a dose increase usually had more severe symptoms at baseline than those who did not request uptitration. Patients with severe symptoms at baseline benefit more from the increased dose [75]. In clinical trials, about $50 \%$ of the patients ask for an increase of the dose of their medication $[40,49]$. Selecting a drug which offers dose flexibility seams a reasonable first-line treatment approach.

3.3.3. Switch between Antimuscarinics. Despite the fact that differences in efficacy of antimuscarinics in clinical trials with large $O A B$ populations are relatively small, an individual patient may benefit more from a particular drug than another. "Salvaging" nonresponders to one drug with another has been shown in several studies. Solifenacin, for example, has been shown to significantly improve bladder diary and validated quality-of-life outcomes in women with urge incontinence that failed to respond or were unable to tolerate oxybutynin IR [75]. Solifenacin treatment in patients with residual urgency after an at-least-four-week course of tolterodine ER $4 \mathrm{mg}$ was associated with significant improvements in urgency and other diary-documented symptoms of OAB. Patients treated with solifenacin also had significant improvements in quality of life scores and the perceived bother of $\mathrm{OAB}$ [76]. In another study, patient's perception of bladder condition (PPBC) score and $\mathrm{OAB}$ symptoms were significantly improved, and satisfaction was high during treatment with darifenacin $(7.5 / 15 \mathrm{mg})$ in patients who were dissatisfied with the previous oxybutynin ER or tolterodine ER treatment [37]. In a recent study [77], patients dissatisfied with tolterodine received fesoterodine $4 \mathrm{mg}$ or $8 \mathrm{mg}$. PPBC, urgency perception scale and the overactive bladder questionnaire $(\mathrm{OAB}-\mathrm{q})$ were significantly improved after 12 weeks of fesoterodine and $80 \%$ of patients became satisfied.

The above studies, despite limitations in patient selection and overall design, suggest that switch between drugs is a reasonable approach in patient failing initial treatment.

3.3.4. Safety in the Male Population. A significant concern when antimuscarinics are considered in male patients with storage lower urinary tract symptoms (LUTS), suggestive of an overactive bladder, is the risk of urinary retention. This concern seems particularly relevant when voiding, benign prostate hyperplasia-related LUTS are present. The reality, nevertheless, is that antimuscarinics at clinically recommended doses have little effect on voiding pressures. Clinical experience has proved that concerns regarding acute urinary retention or increased residual volume are unfounded [78-83]. The incidence of urinary retention is minimal $(<1 \%)$, even in male patients with bladder outflow obstruction, despite the occasional increase in residual urine in certain patients. On the other hand, there are no established criteria for excluding patients at risk for retention from antimuscarinic therapy [81]. More studies with large number of patients, including patients with severe obstruction, are required. In the meantime, it seems reasonable to offer antimuscarinics, either as monotherapy or in combination with $\alpha$-blockers to men with mild-tomoderate obstruction and small residual volumes. The addition of an antimuscarinic to a-blockers has been shown to significantly improve symptoms and quality of life of these patients $[79,81,84,85]$.

\section{Conclusions}

Antimuscarinic agents, as a class, are the cornerstone of medical treatment of overactive bladder. Accumulated evidence from clinical trials and meta-analyses has proved their efficacy and safety. Antimuscarinics offer significant improvements in symptoms of urge incontinence, urgency, frequency, and nocturia. This translates in substantial benefits in quality of life. Antimuscarinics are generally well tolerated with mild and predictable antimuscarinic side effects. The most common and bothersome of them, drymouth, not infrequently leads to treatment discontinuation.

Available antimuscarinics have small, yet statistically significant, differences in their efficacy and tolerability profiles. In general, the higher doses of drugs that offer dose flexibility have higher efficacy. Tolerability depends mainly on drug selectivity for the bladder over other organs, selectivity for muscarinic receptor subtypes and ability to penetrate the CNS. Given that there is no "cure" for OAB yet, finding the agent that offers the optimum balance of efficacy and side effects for an individual patient remains the major challenge in $\mathrm{OAB}$ treatment.

\section{Disclosure}

A. Athanasopoulos is or has been an investigator, lecturer and consultant for pharmaceutical companies producing or developing drugs for lower urinary tract symptoms (Pfizer, Astellas, Ucb, Lilly, Allergan, Bard, and Amgen). K. Giannitsas is or has been an investigator and lecturer for pharmaceutical companies producing or developing drugs for lower urinary tract symptoms (Pfizer, Astellas, Lilly, and Allergan). 


\section{References}

[1] H. Hashim and P. Abrams, "Overactive bladder: an update," Current Opinion in Urology, vol. 17, no. 4, pp. 231-236, 2007.

[2] K.-E. Andersson, "Antimuscarinic mechanisms and the overactive detrusor: an update," European Urology, vol. 59, no. 3, pp. 377-386, 2011.

[3] O. Yamaguchi, "Antimuscarinics and overactive bladder: other mechanism of action," Neurourology and Urodynamics, vol. 29, no. 1, pp. 112-115, 2010.

[4] D. Giglio and G. Tobin, "Muscarinic receptor subtypes in the lower urinary tract," Pharmacology, vol. 83, no. 5, pp. 259-269, 2009.

[5] K. E. Andersson and C. R. Chappie, "Oxybutynin and the overactive bladder," World Journal of Urology, vol. 19, no. 5, pp. 319-323, 2001.

[6] S. De Wachter and J. J. Wyndaele, "Intravesical oxybutynin: a local anesthetic effect on bladder C afferents," Journal of Urology, vol. 169, no. 5, pp. 1892-1895, 2003.

[7] G. W. Davila, "Transdermal oxybutynin: a new treatment for overactive bladder," Expert Opinion on Pharmacotherapy, vol. 4, no. 12, pp. 2315-2324, 2003.

[8] M. A. A. Siddiqui, C. M. Perry, and L. J. Scott, "Oxybutynin extended-release: a review of its use in the management of overactive bladder," Drugs, vol. 64, no. 8, pp. 885-912, 2004.

[9] J. Wefer, M. C. Truss, and U. Jonas, "Tolterodine: an overview," World Journal of Urology, vol. 19, no. 5, pp. 312-318, 2001.

[10] H. Madersbacher and G. Mürtz, "Efficacy, tolerability and safety profile of propiverine in the treatment of the overactive bladder (non-neurogenic and neurogenic)," World Journal of Urology, vol. 19, no. 5, pp. 324-335, 2001.

[11] D. Robinson and L. Cardozo, "The emerging role of solifenacin in the treatment of overactive bladder," Expert Opinion on Investigational Drugs, vol. 13, no. 10, pp. 1339-1348, 2004.

[12] M. Maniscalco, D. Singh-Franco, W. R. Wolowich, and R. Torres-Colón, "Solifenacin succinate for the treatment of symptoms of overactive bladder," Clinical Therapeutics, vol. 28, no. 9, pp. 1247-1272, 2006.

[13] C. R. Chapple, "Darifenacin: a novel M3 muscarinic selective receptor antagonist for the treatment of overactive bladder," Expert Opinion on Investigational Drugs, vol. 13, no. 11, pp. 1493-1500, 2004.

[14] F. Haab, "Darifenacin for the treatment of overactive bladder," Women's Health, vol. 1, pp. 331-343, 2005.

[15] K. Hofner, M. Oelke, S. Machtens, and V. Grünewald, "Trospium chloride-an effective drug in the treatment of overactive bladder and detrusor hyperreflexia," World Journal of Urology, vol. 19, no. 5, pp. 336-343, 2001.

[16] E. S. Rovner, "Trospium chloride in the management of overactive bladder," Drugs, vol. 64, no. 21, pp. 2433-2446, 2004.

[17] M. C. Michel, "Fesoterodine: a novel muscarinic receptor antagonist for the treatment of overactive bladder syndrome," Expert Opinion on Pharmacotherapy, vol. 9, no. 10, pp. 17871796, 2008.

[18] T. Hanawa, C. Tsuchiya, N. Endo et al., "Formulation study of intravesical oxybutynin instillation solution with enhanced retention in bladder," Chemical and Pharmaceutical Bulletin, vol. 56, no. 8, pp. 1073-1076, 2008.

[19] A. C. Diokno, R. A. Appell, P. K. Sand et al., "Prospective, randomized, double-blind study of the efficacy and tolerability of the extended-release formulations of oxybutynin and tolterodine for overactive bladder: results of the OPERA trial," Mayo Clinic Proceedings, vol. 78, no. 6, pp. 687-695, 2003.
[20] R. A. Appell, P. Sand, R. Dmochowski, R. Anderson, and N. Zinner, "Prospective randomized controlled trial of extendedrelease oxybutynin chloride and tolterodine tartrate in the treatment of overactive bladder: results of the OBJECT study," Mayo Clinic Proceedings, vol. 76, no. 4, pp. 358-363, 2001.

[21] P. Sand, N. Zinner, D. Newman et al., "Oxybutynin transdermal system improves the quality of life in adults with overactive bladder: a multicentre, community-based, randomized study," British Journal of Urology International, vol. 99, no. 4, pp. 836-844, 2007.

[22] L. T. Pizzi, A. Talati, E. Gemmen, N. V. Dahl, T. J. Bunz, and P. K. Sand, "Impact of transdermal oxybutynin on work productivity in patients with overactive bladder: results from the MATRIX study," PharmacoEconomics, vol. 27, no. 4, pp. 329-339, 2009.

[23] D. R. Staskin and D. Robinson, "Oxybutynin chloride topical gel: a new formulation of an established antimuscarinic therapy for overactive bladder," Expert Opinion on Pharmacotherapy, vol. 10, no. 18, pp. 3103-3111, 2009.

[24] G. Novara, A. Galfano, S. Secco et al., "A systematic review and meta-analysis of randomized controlled trials with antimuscarinic drugs for overactive bladder," European Urology, vol. 54, no. 4, pp. 740-764, 2008.

[25] J. F. Guest, D. Abegunde, and F. J. Ruiz, "Cost effectiveness of controlled-release oxybutynin compared with immediaterelease oxybutynin and tolterodine in the treatment of overactive bladder in the UK, France and Austria," Clinical Drug Investigation, vol. 24, no. 6, pp. 305-321, 2004.

[26] L. Nilvebrant, B. Hallén, and G. Larsson, "Tolterodine A new bladder selective muscarinic receptor antagonist: preclinical pharmacological and clinical data," Life Sciences, vol. 60, no. 13-14, pp. 1129-1136, 1997.

[27] S. Salvatore, M. Serati, and P. Bolis, "Tolterodine for the treatment of overactive bladder," Expert Opinion on Pharmacotherapy, vol. 9, no. 7, pp. 1249-1255, 2008.

[28] P. Abrams, R. Freeman, C. Anderström, and A. Mattiasson, "Tolterodine, a new antimuscarinic agent: as effective but better tolerated than oxybutynin in patients with an overactive bladder," British Journal of Urology, vol. 81, no. 6, pp. 801-810, 1998.

[29] K. Giannitsas, P. Perimenis, A. Athanasopoulos, K. Gyftopoulos, G. Nikiforidis, and G. Barbalias, "Comparison of the efficacy of tolterodine and oxybutynin in different urodynamic severity grades of idiopathic detrusor overactivity," European Urology, vol. 46, no. 6, pp. 776-782, 2004.

[30] H. Madersbacher and G. Mürtz, "Efficacy, tolerability and safety profile of propiverine in the treatment of the overactive bladder (non-neurogenic and neurogenic)," World Journal of Urology, vol. 19, no. 5, pp. 324-335, 2001.

[31] H. Madersbacher, M. Halaska, R. Voigt, S. Alloussi, and K. Höfner, "A placebo-controlled, multicentre study comparing the tolerability and efficacy of propiverine and oxybutynin in patients with urgency and urge incontinence," British Journal of Urology International, vol. 84, no. 6, pp. 646-651, 1999.

[32] K. P. Jünemann, M. Halaska, T. Rittstein et al., "Propiverine versus tolterodine: efficacy and tolerability in patients with overactive bladder," European Urology, vol. 48, no. 3, pp. 478482, 2005.

[33] H. Madersbacher and G. Mürtz, "Efficacy, tolerability and safety profile of propiverine in the treatment of the overactive bladder (non-neurogenic and neurogenic)," World Journal of Urology, vol. 19, no. 5, pp. 324-335, 2001. 
[34] S. H. Alloussi, G. Murtz, J. Seibold et al., "Antimuscarincs in children: is its use in children evidence-based?" International Urogynecology Journal, vol. 21, supplement 1, p. 428, 2010, abstract 292.

[35] K. S. Lee, H. W. Lee, M. S. Choo et al., "Urinary urgency outcomes after propiverine treatment for an overactive bladder: the 'Propiverine study on overactive bladder including urgency data," British Journal of Urology International, vol. 105, no. 11, pp. 1565-1570, 2010.

[36] P. Dwyer, C. Kelleher, J. Young et al., "Long-term benefits of darifenacin treatment for patient quality of life: results from a 2-year extension study," Neurourology and Urodynamics, vol. 27, no. 6, pp. 540-547, 2008.

[37] N. Zinner, K. C. Kobashi, U. Ebinger et al., "Darifenacin treatment for overactive bladder in patients who expressed dissatisfaction with prior extended-release antimuscarinic therapy," International Journal of Clinical Practice, vol. 62, no. 11, pp. 1664-1674, 2008.

[38] P. Abrams and S. Swift, "Solifenacin is effective for the treatment of OAB dry patients: a pooled analysis," European Urology, vol. 48, no. 3, pp. 483-487, 2005.

[39] P. Herbison, J. Hay-Smith, G. Ellis, and K. Moore, "Effectiveness of anticholinergic drugs compared with placebo in the treatment of overactive bladder: systematic review," British Medical Journal, vol. 326, no. 7394, pp. 841-844, 2003.

[40] C. R. Chapple, R. Martinez-Garcia, L. Selvaggi et al., "A comparison of the efficacy and tolerability of solifenacin succinate and extended release tolterodine at treating overactive bladder syndrome: results of the STAR trial," European Urology, vol. 48, no. 3, pp. 464-470, 2005.

[41] L. Cardozo, E. Heßdörfer, R. Milani et al., "Solifenacin in the treatment of urgency and other symptoms of overactive bladder: results from a randomized, double-blind, placebocontrolled, rising-dose trial," British Journal of Urology International, vol. 102, no. 9, pp. 1120-1127, 2008.

[42] M. M. Karram, M. R. Toglia, S. R. Serels, M. Andoh, A. Fakhoury, and S. Forero-Schwanhaeuser, "Treatment with solifenacin increases warning time and improves symptoms of overactive bladder: results from VENUS, a randomized, double-blind, placebo-controlled trial," Urology, vol. 73, no. 1, pp. 14-18, 2009.

[43] N. Zinner, M. Gittelman, R. Harris, J. Susset, A. Kanellos, and S. Auerbach, "Trospium chloride improves overactive bladder symptoms: a multicenter phase III trial," Journal of Urology, vol. 171, no. 6 I, pp. 2311-2315, 2004.

[44] L. Cardozo, V. Mirone, C. Gratzke, and M. Marberger, "Extended-release trospium chloride $60 \mathrm{mg}$ - a new oncedaily medication for the treatment of overactive bladder syndrome," European Urological Review, vol. 5, no. 1, pp. 3-6, 2010.

[45] V. Nitti, M. Wiatrak, L. Kreitman, and D. Lipsitz, Fesoterodine is an effective antimuscarinic for patients with overactive bladder $(\mathrm{OAB}) \mathrm{Q}$ results of a phase 2 trial. Paper presented at International Continence Society Montreal, Canada, 2005.

[46] C. Chapple, P. Van Kerrebroeck, A. Tubaro et al., "Clinical efficacy, safety, and tolerability of once-daily fesoterodine in subjects with overactive bladder," European Urology, vol. 52, no. 4, pp. 1204-1212, 2007.

[47] S. A. Kaplan, T. Schneider, J. E. Foote, Z. Guan, M. Carlsson, and J. Gong, "Superior efficacy of fesoterodine over tolterodine extended release with rapid onset: a prospective, headto-head, placebo-controlled trial," British Journal of Urology International, vol. 107, no. 9, pp. 1432-1440, 2011.
[48] S. Herschorn, S. Swift, Z. Guan et al., "Comparison of fesoterodine and tolterodine extended release for the treatment of overactive bladder: a head-to-head placebo-controlled trial," British Journal of Urology International, vol. 105, no. 1, pp. 58-66, 2010.

[49] J.-J. Wyndaele, E. R. Goldfischer, J. D. Morrow et al., "Effects of flexible-dose fesoterodine on overactive bladder symptoms and treatment satisfaction: an open-label study," International Journal of Clinical Practice, vol. 63, no. 4, pp. 560-567, 2009.

[50] C. Chapple, V. Khullar, Z. Gabriel, and J. A. Dooley, "The effects of antimuscarinic treatments in overactive bladder: a systematic review and meta-analysis," European Urology, vol. 48, no. 1, pp. 5-26, 2005.

[51] C. R. Chapple, V. Khullar, Z. Gabriel, D. Muston, C. E. Bitoun, and D. Weinstein, "The effects of antimuscarinic treatments in overactive bladder: an update of a systematic review and metaanalysis," European Urology, vol. 54, no. 3, pp. 543-562, 2008.

[52] C. R. Chapple, V. Khullar, Z. Gabriel, D. Muston, C. E. Bitoun, and D. Weinstein, "The effects of antimuscarinic treatments in overactive bladder: an update of a systematic review and metaanalysis," European Urology, vol. 54, no. 3, pp. 543-562, 2008.

[53] L. P. W. Witte, W. M. C. Mulder, J. J. M. C. H. De La Rosette, and M. C. Michel, "Muscarinic receptor antagonists for overactive bladder treatment: does one fit all?" Current Opinion in Urology, vol. 19, no. 1, pp. 13-19, 2009.

[54] R. Millard, J. Tuttle, K. Moore et al., "Clinical efficacy and safety of tolterodine compared to placebo in detrusor overactivity," Journal of Urology, vol. 161, no. 5, pp. 1551-1555, 1999.

[55] Y. E. Yarker, K. L. Goa, and A. Fitton, “Oxybutynin. A review of its pharmacodynamic and pharmacokinetic properties, and its therapeutic use in detrusor instability," Drugs \& Aging, vol. 6, no. 3, pp. 243-262, 1995.

[56] P. D. Meek, S. D. Evang, M. Tadrous, D. Roux-Lirange, D. M. Triller, and B. Gumustop, "Overactive bladder drugs and constipation: a meta-analysis of randomized, placebocontrolled trials," Digestive Diseases and Sciences, vol. 56, no. 1, pp. 7-18, 2011.

[57] G. Kay, T. Crook, L. Rekeda et al., "Differential effects of the antimuscarinic agents darifenacin and oxybutynin ER on memory in older subjects," European Urology, vol. 50, no. 2, pp. 317-326, 2006.

[58] R. B. Lipton, K. Kolodner, and K. Wesnes, "Assessment of cognitive function of the elderly population: effects of darifenacin," Journal of Urology, vol. 173, no. 2, pp. 493-498, 2005.

[59] G. G. Kay and U. Ebinger, "Preserving cognitive function for patients with overactive bladder: evidence for a differential effect with darifenacin," International Journal of Clinical Practice, vol. 62, no. 11, pp. 1792-1800, 2008.

[60] D. Staskin, G. Kay, C. Tannenbaum et al., "Trospium chloride is undetectable in the older human central nervous system," Journal of the American Geriatrics Society, vol. 58, no. 8, pp. 1618-1619, 2010.

[61] B. Malhotra, K. Gandelman, R. Sachse, N. Wood, and M. C. Michel, "The design and development of fesoterodine as a prodrug of 5-hydroxymethyl tolterodine (5-HMT), the active metabolite of tolterodine," Current Medicinal Chemistry, vol. 16, no. 33, pp. 4481-4489, 2009.

[62] B. Olshansky, U. Ebinger, J. Brum, M. Egermark, A. Viegas, and L. Rekeda, "Differential pharmacological effects of antimuscarinic drugs on heart rate: a randomized, placebocontrolled, double-blind, crossover study with tolterodine and 
darifenacin in healthy participants $\geq 50$ years," Journal of Cardiovascular Pharmacology and Therapeutics, vol. 13, no. 4, pp. 241-251, 2008.

[63] D. B. Serra, M. B. Affrime, M. P. Bedigian et al., "QT and QTc interval with standard and supratherapeutic doses of darifenacin, a muscarinic $M$ selective receptor antagonist for the treatment of overactive bladder," Journal of Clinical Pharmacology, vol. 45, no. 9, pp. 1038-1047, 2005.

[64] R. M. Hussain, K. Hartigan-Go, S. H. L. Thomas, and G. A. Ford, "Effect of oxybutynin on the QTc interval in elderly patients with urinary incontinence," British Journal of Clinical Pharmacology, vol. 41, no. 1, pp. 73-75, 1996.

[65] B. K. Malhotra, P. Glue, K. Sweeney, R. Anziano, J. Mancuso, and P. Wicker, "Thorough QT study with recommended and supratherapeutic doses of tolterodine," Clinical Pharmacology and Therapeutics, vol. 81, no. 3, pp. 377-385, 2007.

[66] Y. Homma and O. Yamaguchi, "A randomized, doubleblind, placebo- and propiverine-controlled trial of the novel antimuscarinic agent imidafenacin in Japanese patients with overactive bladder," International Journal of Urology, vol. 16, no. 5, pp. 499-506, 2009.

[67] B. Malhotra, N. Wood, R. Sachse, and K. Gandelman, "Thorough QT study of the effect of fesoterodine on cardiac repolarization," International Journal of Clinical Pharmacology and Therapeutics, vol. 48, no. 5, pp. 309-318, 2010.

[68] M. C. Michel, U. Wetterauer, M. Vogel, and J. J. De La Rosette, "Cardiovascular safety and overall tolerability of solifenacin in routine clinical use: a 12-week, open-label, post-marketing surveillance study," Drug Safety, vol. 31, no. 6, pp. 505-514, 2008.

[69] C. L. G. Sears, C. Lewis, K. Noel, T. S. Albright, and J. R. Fischer, "Overactive bladder medication adherence when medication is free to patients," Journal of Urology, vol. 183, no. 3, pp. 1077-1081, 2010.

[70] A. O. D’Souza, M. J. Smith, L. A. Miller, J. Doyle, and R. Ariely, "Persistence, adherence, and switch rates among extendedrelease and immediate-release overactive bladder medications in a regional managed care plan," Journal of Managed Care Pharmacy, vol. 14, no. 3, pp. 291-301, 2008.

[71] R. Peeker, G. Samsioe, J. Kowalski, A.-S. Andersson, and A. Bergqvist, "A prospective observational study of the effects of treatment with extended-release tolterodine on healthrelated quality of life of patients suffering overactive bladder syndrome in Sweden," Scandinavian Journal of Urology and Nephrology, vol. 44, no. 3, pp. 138-146, 2010.

[72] C. R. Chapple, A. Fianu-Jonsson, M. Indig et al., "Treatment outcomes in the STAR study: a subanalysis of solifenacin $5 \mathrm{mg}$ and tolterodine ER 4 mg," European Urology, vol. 52, no. 4, pp. 1195-1203, 2007.

[73] F. Haab and D. Castro-Diaz, "Persistence with antimuscarinic therapy in patients with overactive bladder," International Journal of Clinical Practice, vol. 59, no. 8, pp. 931-937, 2005.

[74] J. S. Benner, M. B. Nichol, E. S. Rovner et al., "Patient-reported reasons for discontinuing overactive bladder medication," British Journal of Urology International, vol. 105, no. 9, pp. 1276-1282, 2010.

[75] C. R. Chapple, M. T. Rosenberg, and F. J. Brenes, "Listening to the patient: a flexible approach to the use of antimuscarinic agents in overactive bladder syndrome," British Journal of Urology International, vol. 104, no. 7, pp. 960-967, 2009.

[76] M. B. Chancellor, N. Zinner, K. Whitmore et al., "Efficacy of solifenacin in patients previously treated with tolterodine extended release $4 \mathrm{mg}$ : results of a 12-week, multicenter, openlabel, flexible-dose study," Clinical Therapeutics, vol. 30, no. 10, pp. 1766-1781, 2008.

[77] J.-J. Wyndaele, E. R. Goldfischer, J. D. Morrow, J. Gong, L.-J. Tseng, and M.-S. Choo, "Patient-optimized doses of fesoterodine improve bladder symptoms in an open-label, flexible-dose study," British Journal of Urology International, vol. 107, no. 4, pp. 603-611, 2011.

[78] A. Athanasopoulos and P. Perimenis, "Efficacy of the combination of an $\alpha 1$-blocker with an anticholinergic agent in the treatment of lower urinary tract symptoms associated with bladder outlet obstruction," Expert Opinion on Pharmacotherapy, vol. 6, no. 14, pp. 2429-2433, 2005.

[79] A. Athanasopoulos, "Antimuscarinics and bladder outlet obstruction: from a contraindication to an indication?" $\mathrm{Neu}$ rourology and Urodynamics, vol. 29, supplement 1, pp. S46S50, 2010.

[80] A. Athanasopoulos, D. Mitropoulos, K. Giannitsas, and P. Perimenis, "Safety of anticholinergics in patients with benign prostatic hyperplasia," Expert Opinion on Drug Safety, vol. 7, no. 4, pp. 473-479, 2008.

[81] C. Chapple, "Antimuscarinics in men with lower urinary tract symptoms suggestive of bladder outlet obstruction due to benign prostatic hyperplasia," Current Opinion in Urology, vol. 20, no. 1, pp. 43-48, 2010.

[82] C. Füllhase, R. Soler, C. Gratzke, M. Brodsky, G. J. Christ, and K. E. Andersson, "Urodynamic evaluation of fesoterodine metabolite, doxazosin and their combination in a rat model of partial urethral obstruction," British Journal of Urology International, vol. 106, no. 2, pp. 287-293, 2010.

[83] G. Conte-Santos, M. Rebbassa-Llull, L. Soriano-Burrull et al., "Study of safety and urodynamic characteriztion of treatment with tamsulosin, tolderodine and tamsulosin plus tolderodine, in men with LUTS," European Urology, vol. 8, no. 4, p. 237, 2009, abstract 468 .

[84] B. T. Blake-James, A. Rashidian, Y. Ikeda, and M. Emberton, "The role of anticholinergics in men with lower urinary tract symptoms suggestive of benign prostatic hyperplasia: a systematic review and meta-analysis," British Journal of Urology International, vol. 99, no. 1, pp. 85-96, 2007.

[85] G. Novara, A. Galfano, V. Ficarra, and W. Artibani, "Anticholinergic drugs in patients with bladder outlet obstruction and lower urinary tract symptoms: a systematic review," European Urology, vol. 50, no. 4, pp. 675-683, 2006. 


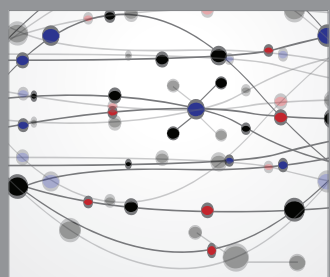

The Scientific World Journal
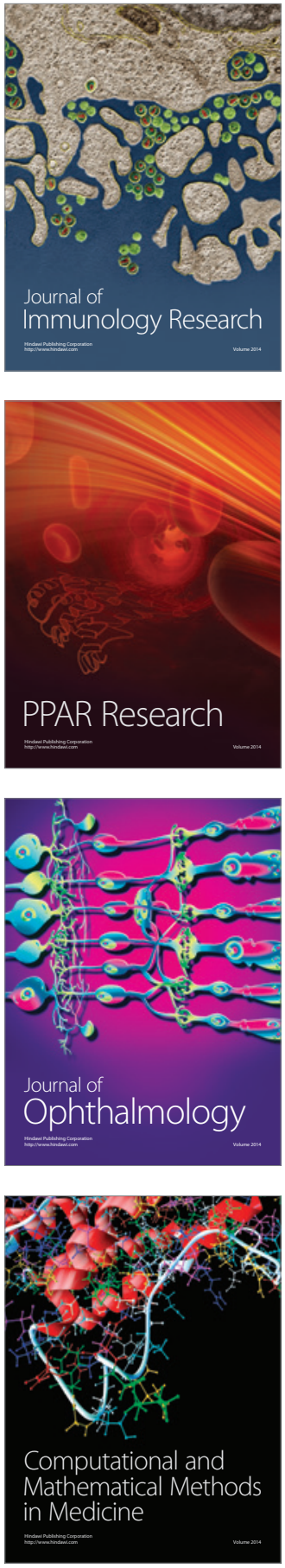

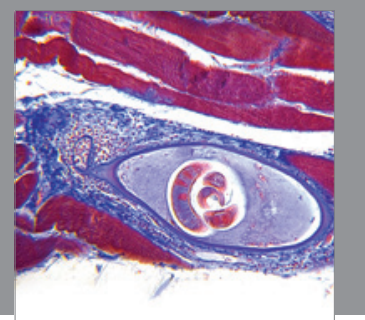

Gastroenterology

Research and Practice
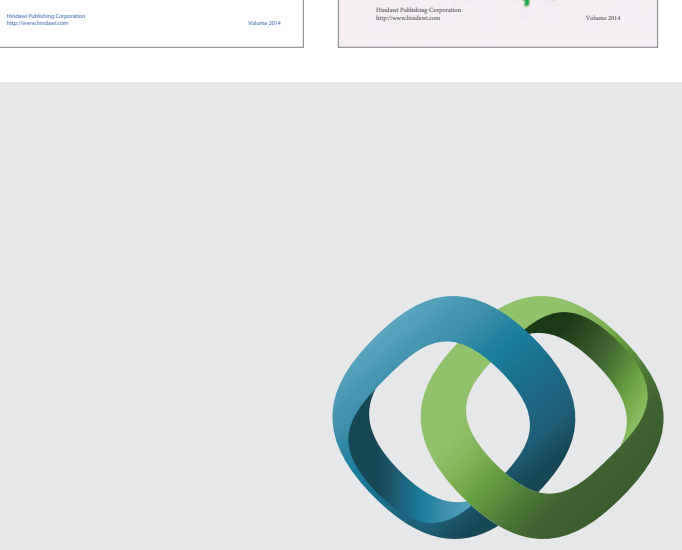

\section{Hindawi}

Submit your manuscripts at

http://www.hindawi.com
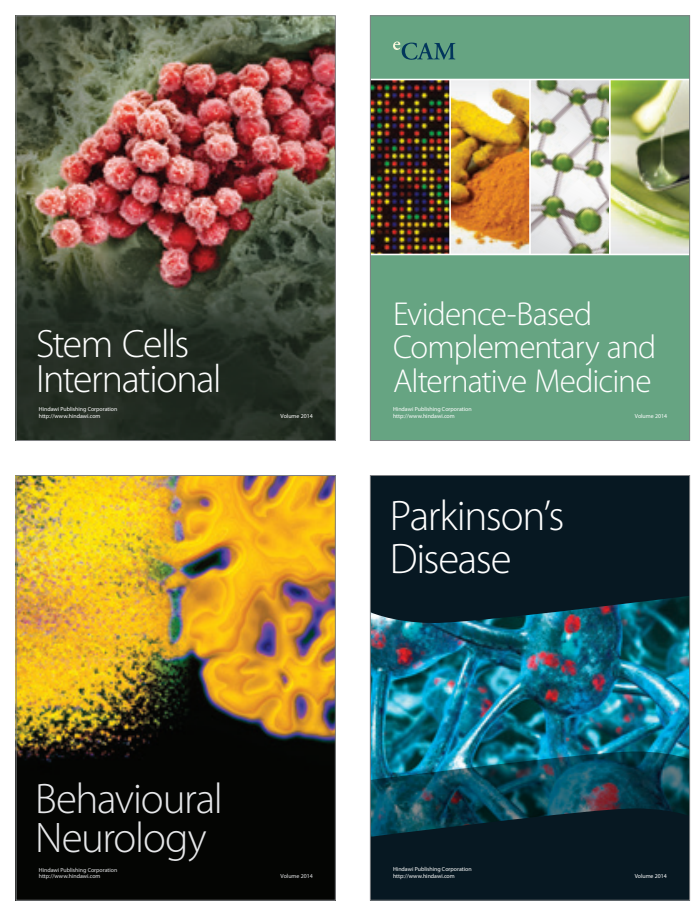

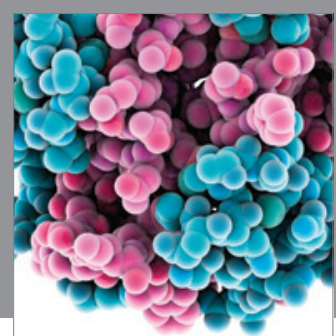

Journal of
Diabetes Research

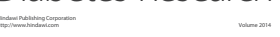

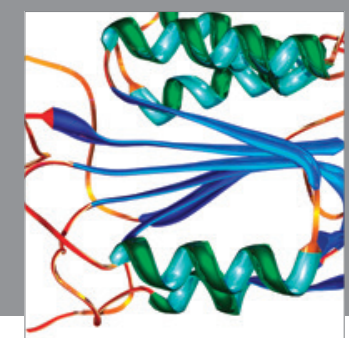

Disease Markers
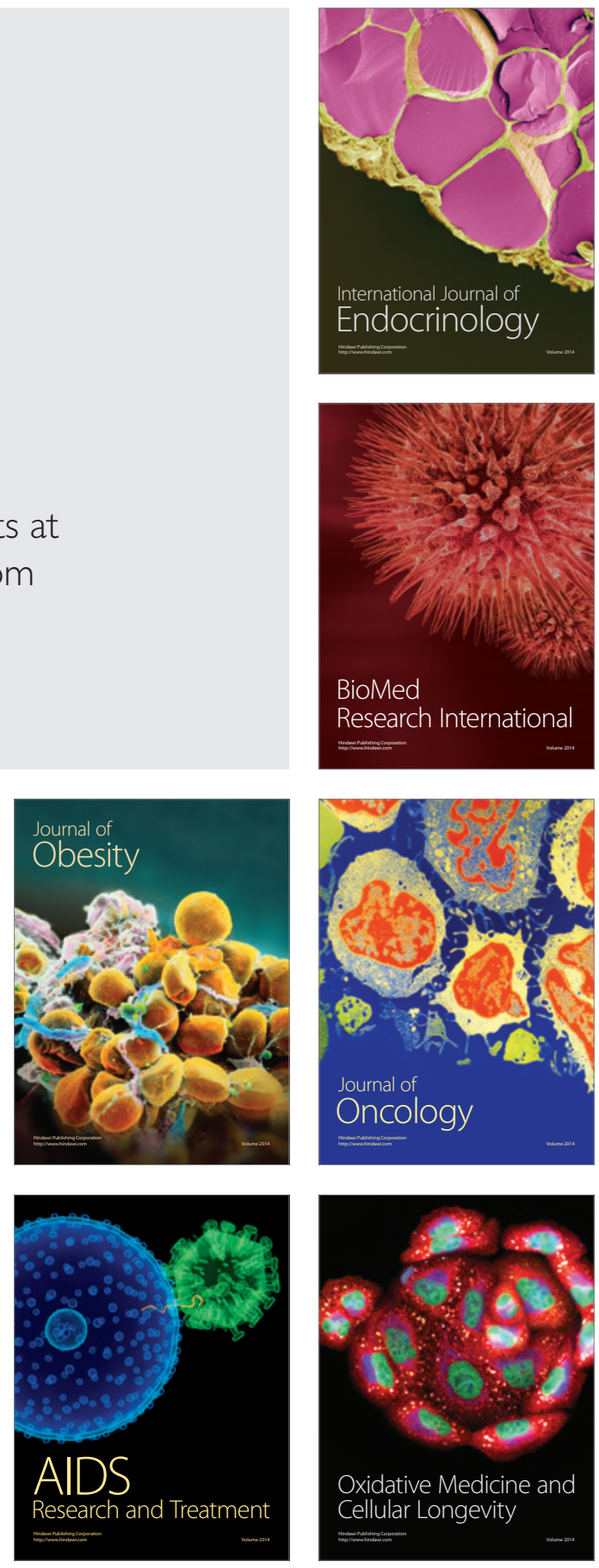